\title{
Crime Victims and the Right to Punishment
}

\author{
David Alm ${ }^{1}$ (D)
}

Published online: 20 March 2018

(C) The Author(s) 2018

\begin{abstract}
In this paper, I consider the question of whether crime victims can be said to have a moral right to see their victimizers punished (a "right to punishment") that could explain why they often feel wronged or cheated when the state fails to punish offenders (or even to make such conduct punishable). In the first part, I explain what I mean by a "right to punishment" and what it is for such a right to "explain" the frustrated crime victim's reaction. In the second part, I distinguish such a right from a Lockean-style right to punish, which is also shown incapable of providing the needed explanation. In the third part I argue that it is difficult to identify any benefit such that the right to punishment could plausibly be understood as a right to that benefit. I discuss two main candidates here: (i) the vaguely Hegelian idea that punishment is itself some sort of restitution for the wrong done to the victim; and (ii) the idea, due to Victor Tadros, that punishment is a form of compensation for wrongdoing by contributing indirectly to protecting victims from future harm. In the final section, I suggest instead that the frustrated crime victim's reaction, when justified, is best explained, not by the violation of any right to punishment, but rather by the state's failure to treat the victim as an equal.
\end{abstract}

Keywords Punishment $\cdot$ Victims $\cdot$ Rights $\cdot$ Equality

Imagine that you are the victim of a serious crime, and that you know who the offender is. Suppose also that this individual is not convicted of the crime, and so not punished. How would you react? No doubt your response will depend on the precise reason why the culprit evades justice, but most likely you will be unhappy.

David Alm

David.Alm@fil.lu.se

1 Department of Philosophy, University of Lund, P.O. Box 192, 22100 Lund, Sweden 
You may feel unfairly treated, cheated, even wronged, as if the criminal's initial wrongdoing were compounded by the system's inability to do justice. Any satisfactory account of punishment must be able to make sense of such reactions. Their naturalness, together with the fact that we do not expect a similar reaction from just anyone, strongly suggest that you have indeed been wronged in some way. At any rate, I will not entertain the possibility that your reaction is simply mistaken. It is to be explained, not explained away. The most straightforward explanation is that you have a claim right of some sort against the state that the person who wronged you be punished (henceforth: a right to punishment). The aim of this paper is to explore that proposed explanation. I will argue that there is strictly speaking no such right, and that the frustrated crime victim's reaction is better explained differently.

I will begin by clarifying the question posed (i.e., of whether we can explain the frustrated crime victim's reaction by appeal to a right to punishment). To forestall confusion, I then pause briefly, in Sect. 2, to explain the difference between such a right and John Locke's "right to punish." In Sect. 3, I inquire rather skeptically into the possibility of identifying a benefit to the crime victim such that the right to punishment could plausibly be understood as a right to that benefit. In the final section, I turn to an alternative explanation of the frustrated crime victim's reaction in terms of a right to equal treatment (understood in a certain way to be explained).

\section{The Right to Punishment}

Our question needs clarification in two respects. First, how are we to understand the crime victim's supposed "right to punishment"; and second, what is involved in that right's "explaining" the frustrated victim's reaction? Let me now address these two matters in order.

As far as the right to punishment is concerned, I begin at a general level. That is, I will first address the notion of a right to which I will be appealing, before saying something about the right to punishment specifically. To make my denial of the right to punishment as interesting as possible, I will employ a fairly minimal conception of a right. In particular, I am interested only in that aspect of the ordinary philosophical notion of a moral right needed to justify the frustrated crime victim's sense of having been wronged by the state's failure to punish the offender. To provide that explanation, it is necessary and sufficient to note that a right corresponds to a duty to the right holder (as opposed to an impersonal duty). However, I will not commit myself to any specific account of the peculiar relational, or directed, nature of this duty, including the so-called "interest" and "benefit" theories of relationality, or any of their variants. Nor will I suppose that a right has to be either enforceable, in the sense that its possessor is licensed to resort to otherwise impermissible means to ensure compliance by the duty bearer, or peremptory, in the sense suggested by Raz (1986). Nor, for that matter, will I assume that a right is waivable. Some readers might worry that the notion left to us once these qualifications are made is too anemic to merit the label 'right'. I do not wish to argue over a word, and so invite those who share the worry to substitute for 'right' the (to my ear at least) weaker term "claim'. However, I will continue to speak of a "right to punishment." 
On a related note, other readers may complain that we should eschew talk of rights in the present context, and say instead that the frustrated victim can complain at the state's failure to do justice. Again, I am not out to court controversy. I will suppose that my notion of a right is general enough to encompass that of justice. (Cf. our talking of "claims of justice.") Or, rather, I will do so if injustice is understood as consisting in wronging someone, and not purely impersonally, as a sort of undesirable state of affairs.

Turning now to the right to punishment specifically, I note that, like any right, it has two (or three) central components: (a) a content: what is it a right to? (b) a duty bearer: who is it a right against? (c) a strength. The last of the three is disputed, as some philosophers deny that rights have strength. ${ }^{1}$ I wish to be neutral in this debate. However, if the right to punishment does have strength, it is in any case hard to say anything useful at a general level about its magnitude. Therefore, I will assert only this: insofar as the frustrated crime victim's reaction is justified, the duty corresponding to this right is not overridden. In saying this, I take myself to be neutral on whether there are justified right infringements. What I do assume is that the victim of a justified infringement, if such there be, is not wronged in the relevant sense and does not have reason to feel wronged in the way the frustrated crime victim does. As I said in the introduction that I take that reaction to be typically justified, it follows that the corresponding right, if there is one, is also typically not overridden.

It is possible to capture both of the other two components of the right to punishment (i.e., content and duty bearer) with the following definition of legal punishment, which I take to be fairly standard: "the imposition of something that is intended to be both burdensome and reprobative, on a supposed offender for a supposed crime, by a person or body who claims the authority to do so" (Duff 2016, Sect. 1). Specifically, I will assume that a crime victim's right to punishment corresponds to a state obligation to impose legal punishment in the sense just defined on the perpetrator of the crime in question. Such a definition of the content of the right to punishment may seem unsuitable because it excludes certain phenomena, such as most particularly punishment in a Lockean state of nature. However, there is actually little harm in our employing such a relatively narrow definition, and I will do so. The reason why such a restriction is harmless is precisely that our focus is the right supposedly belonging to the frustrated crime victim; for I assert that, even if the notion of punishment in a Lockean state of nature makes sense (and I do not deny this), the failure of its members to punish wrongdoing does not wrong the victim of that wrongdoing, and a reaction like that of the frustrated crime victim would be unwarranted (if it occurred at all). In making such an assertion, I obviously rely on an intuition that could be disputed. Yet the thesis we started with-that the state's failure to punish a crime wrongs the victim of that crime-is not obviously in any better shape. If we may grant the latter intuition about state punishment for the sake of the discussion, we are equally entitled to the former one about state-of-nature punishment.

\footnotetext{
$\overline{{ }^{1} \text { I have in mind so-called "specificationists," such as Wellman (1995). }}$
} 
In one way, the right to punishment is naturally understood as broader than I have made it appear thus far. The state has two tasks in which potential victims of wrongdoing are likely to take an interest: the first is to criminalize certain types of action that wrong others. The second is to punish those who violate the resulting prohibitions. As a consequence, and depending on circumstances, a frustrated victim of a particular instance of wrongdoing could complain either that the state has failed to criminalize wrongs like the one inflicted upon him, or that it has failed to punish that same action token despite having criminalized the relevant type. While there are certainly important differences between these complaints, for simplicity, I choose here to disregard these. Hence, and granting at least for argument's sake that retroactive punishment is not an option, the right to punishment is naturally understood as comprising a right to both criminalization and punishment. I will continue, again out of convenience, to refer to the "frustrated crime victim's complaint," but we have to remember that the term 'crime victim' is here used in an admittedly artificially wide sense to refer not only to victims of actual crime, but also to persons within a state who are made victims of non-criminal wrongdoing — or at least non-criminal wrongdoing that should be made criminal. Such a person can often plausibly complain that the state should first have criminalized such wrongdoing and then punished the individual who wronged him in particular.

A final caveat about the right to punishment may be called for. I am concerned here exclusively with the victim's right to punishment as explained above, and not with the miscellany of other rights that have often been attributed to crime victims, under the heading "victim's rights." Hence, I will set aside the question of which role, if any, a crime victim is entitled to play in the criminal justice process, and which power over that process he is entitled to have.

I turn now to the thesis that we can explain the frustrated crime victim's sense of having been wronged by appeal to a right to punishment. Here, an explanation amounts to, or at least contributes to, a justification of the reaction. The right to punishment, then, must be able to play that justificatory role. But what does that mean? Let me make a few remarks that will hopefully suffice to delineate the notion I am after. I begin with a negative point: even if it is true that the victim's right justifies his reaction, it does not follow that it also contributes to a justification of the punishment itself, nor that the existence of such rights generally contribute to a justification of the practice of punishment. Talk of the justification of a practice is admittedly ambiguous. ${ }^{3}$ In particular, we might have in mind either a "rational" justification, providing a rationale for or a point to engaging in the practice at all (such as deterring others or giving people their just deserts); or a "moral" justification, showing why the practice is morally permissible, and in particular why it does not infringe, or at least not violate, anyone's rights. However, I hold that a justification of the frustrated crime victim's reaction need not contribute to a justification of the

\footnotetext{
${ }^{2}$ See, e.g., Whiteley (1998) and Barton (1999) for philosophical treatments of this broader class of rights.

${ }^{3}$ See Dolinko (1991, p. 539) for the distinction between rational and moral justification employed in this paragraph.
} 
practice in either of these senses. Indeed, I would go further and maintain that the former justification does not contribute to either of the latter. I remind doubtful readers that I have in effect supposed that the right to punishment is conditional on the existence of the state. If so, then it could not by itself justify a practice that is often seen as constitutive of the state itself. (I will return to this matter in Sect. 4.)

Even so, we can still agree that a justification of the victim's reaction presupposes (i.e., logically implies) at least the moral justification of the practice. That is, the frustrated victim's resentful reaction at the absence of punishment is in place only if the offender's right is not violated by the presence of punishment. By the same token, the victim's right to punishment is itself contingent on such a justification. If so, a complete justification of the crime victim's reaction requires some explanation of why offenders are not wronged by punishment. I will not address the nature of that explanation in this paper. Also, if as some writers hold, punishment is morally justified only if it is rationally justified-and I do not wish to take a stand on that issue-then a justification of the reaction presupposes such a rational justification of the practice as well. ${ }^{4}$

Positively, I note that for the right to justify the frustrated crime victim's reaction, it must itself have an "individualistic justification," meaning that "the duty [corresponding to the right] is grounded by something about the person to whom it is owed, so violating it involves failing to respond to a duty-grounding aspect of that person." ${ }^{5}$ Only then, it seems, is a reaction like that of the frustrated crime victim's justified, or even understandable. An important arguable implication of this demand, on which I will not comment further, is that the right to punishment could not be justified by "indirect" accounts of rights generally, such as consequentialism or contractarianism. In other words, it rules out justifying the right by appeal to the (purported) fact that a convention of treating crime victims as entitled to punishment is (ex-ante) beneficial either for society in the aggregate or for each individual.

Let me make a final caveat: I will ignore the special case of murder, and other criminal acts that cause death. Any attempt to justify punishment for murder that appeals, even in part, to a right of the victim's commits us to the existence of rights belonging to dead persons. Such a claim obviously raises special difficulties that I prefer not to address. To make matters simpler, I will therefore suppose throughout that we are dealing only with non-lethal crimes. While this restriction is certainly quite significant, it is not dialectically problematic as my aim is to criticize rather than defend the right to punishment. Therefore, abstracting from a phenomenon that, if anything, makes such a right harder to defend seems legitimate.

\footnotetext{
${ }^{4}$ For a clear endorsement of the view referred to in the text (though using different jargon), see McMahan (2009, pp. 8-10).

5 I quote Cruft (2013, p. 207), from whom I borrow the term 'individualistic justification'.
} 


\section{The Lockean Strategy}

In this section, I address an indirect way of accounting for the frustrated crime victim's reaction. ${ }^{6}$ It is indirect in that it does not appeal to a right to punishment, as described in the preceding section, but rather to a somewhat different right. This maneuver avoids the problems I discuss in Sect. 3 and explains why the purported right is conditional on the existence of the state, as I have claimed. I have in mind the Lockean view of punishment. ${ }^{7}$ On this view, individuals in the state of nature have a right to punish those who wrong them, and indeed also those who wrong others. This right is most plausibly understood as a negative right against third parties, and perhaps against the offender himself, not to interfere with the victim's retaliation against the offender. Further, an essential element of the transformation of the state of nature into civil society, and so of the social contract, is that the individuals transfer their right to punishment to the state. Thereby, they are typically no longer entitled to seek retaliation privately for the wrongs they suffer, but rather trust the state to provide it for them by means of criminalization and punishment. Should the state therefore fail to do so in a given case, it has reneged on its part of the bargain with the victim in question - at any rate if it also insists on prohibiting and punishing that person's private retaliation.

It should be clear that this account of punishment explains why the frustrated crime victim has reason to resent the state for its failure to criminalize or punish, provided it also prevents his attempts to retaliate privately. It can also explain why this resentment only makes sense against the state, and not against one's fellows in the state of nature - as long as they simply refuse to punish one's victimizer, or even to aid one in punishing him oneself. Yet, it seems to me that the Lockean view cannot offer the explanation we need.

I set aside here the worry that Locke's view cannot explain why the frustrated crime victim's reaction is properly his alone, given that supposedly all persons in the state of nature share his right to punish. For perhaps we can simply modify the view to say that the right to punish, as opposed to a mere liberty, does belong to the victim alone. That modification is in any case plausible. Suppose that in the state of nature I attempt to punish the villain who victimized you, and that for some reason a stranger interferes with my activity. While the stranger's interference may possibly wrong you, the victim, it hardly wrongs me (as long as it does not infringe any independent right of mine).

The main problem with the Lockean answer to our question is rather that it cannot account for the sense that it is precisely the state's failure to punish (or to criminalize) that wrongs the victim. The right to punishment is positive. On the Lockean picture, however, it is ultimately the active interference with private retaliation that gives cause for resentment, not the mere failure to punish. ${ }^{8}$ After all, the Lockean

\footnotetext{
${ }^{6}$ I am grateful to Wlodek Rabinowicz for pressing me on this issue.

7 The origin of this view is in Locke's Second Treatise on Government (1690), Chapter 2. For a noteworthy recent account and defense of it, see Simmons (1991).

${ }^{8}$ Cf. Kershnar (2000).
} 
does not appeal directly to any positive right to punishment. The explanation of the frustrated crime victim's reaction is indirect, appealing instead to the victim's negative right to non-interference with his own retaliation. Suppose that the victim is unable to seek private retaliation, for reasons that themselves involve no violation of any right of his, and (if it matters) that the state would not have prevented him from doing so had he been able. It is hard to see how the Lockean can account for the victim's grievance in such a case, in which the state merely refrains from punishment (or criminalization). (We will return to this type of situation in Sect. 4.) Yet even this grievance may still seem real.

Also, the Lockean will find it hard to account for one component of our definition of (legal) punishment from Sect. 1, namely the reprobative element. More specifically, the right to punishment may also be seen as a right to the reprobative nature of the state's response to the crime, something that could not be accomplished by private retaliation, and that could hardly exist at all in the state of nature. A crime victim will want not just for the offender to suffer hard treatment, but also for him to be subject to official, and public, condemnation. To the extent that the frustrated victim's reaction is due to the non-occurrence of this condemnation, it is hard to see how to make sense of it on the Lockean view. ${ }^{9}$

\section{Punishment as a Benefit}

I turn now to the idea that the frustrated crime victim's reaction indeed answers to the violation of a right. As already noted, any such right would evidently have to be positive, in the sense that it requires the state to take positive action, by punishing the offender (having first criminalized his action). We can usefully divide positive rights into two categories. On the one hand, there are rights to a benefit of some sort. In some sense, perhaps, satisfying a person's right is beneficial for him just as such, or infringing it is harmful. Whether that is so or not, here I have in mind something that is beneficial quite independently of its being the object of a right, such that the benefit can help explain the right. On the other hand, are rights to treatment that does not confer such an independent benefit. I will be concerned in this section with rights of the first of these two kinds, postponing consideration of the second kind until the final section.

What we need to be looking for, then, is an independent benefit to the crime victim-and not to society or some sort of impersonal benefit-such that the right to punishment could plausibly be taken to be a right to that benefit. Let me begin by rather quickly setting aside two candidates for such a benefit whose plausibility is

\footnotetext{
9 In this note, I briefly address another possible way of interpreting the right to punishment, namely as resulting from a kind of promise made by the state (but not, necessarily, by persons in the state of nature). This proposal is problematic, both because it is hard to see how it could account for the right to criminalization, which we have assumed to be part of the right to punishment and because it is unclear to what extent the state can be said to have promised (or acquired an obligation) to punish even those acts it has in fact criminalized, if it does not actually do so as a matter of practice. (I will return to this last point in Sect. 4.).
} 
merely apparent. In the first place, then, we might try deriving the right to punishment from a purported right to various psychological benefits that punishment may afford the victim (such as "closure"). ${ }^{10}$ Arguably, though, a frustrated victim's reaction would be justified even in the case in which he would not in fact have enjoyed these benefits if, contrary to fact, the offender had been punished-meaning that the state's failure to punish has not deprived him of these benefits. Also, perhaps the psychological benefits could be secured without punishment, as for instance by various forms of therapy, or even drugs. If so, the derivation purportedly leading to the right to punishment breaks down, yet that right might still seem genuine. Hence, receiving the benefits is neither necessary nor sufficient for having one's right to punishment satisfied. Second, the right to punishment might be thought to be derived from a right against the state that it take effective means of protecting citizens against violations of their other rights. Hence, if a regime of punishment is such an effective means (but not otherwise), citizens could have a right to it. Now, I am willing to grant, at least arguendo, that the presence of this benefit is necessary for the frustrated crime victim's reaction to be justified; in that respect, then, it differs from the psychological benefits. The reason for its inability to account for the frustrated crime victim's reaction is rather that the right to this benefit, which I do not question, does not belong to actual crime victims exclusively. Any citizen can demand that the state take effective measures to combat crime-but not any citizen has reason to react the way a frustrated crime victim does.

In the rest of this section, I will instead consider two other suggestions from the philosophical literature on punishment that purport to identify a benefit of the type we want. Though they are rather different from one another, they have one thing in common, for they both hold that the benefit punishment confers is a form of compensation for a loss caused by the original offense. For our purposes, this appeal to compensation has the obvious advantage of providing support for the crucial idea that the victim has a right to whatever benefit is at stake, that it is not merely a good thing that we have reason to provide. After all, the general idea of a "right to compensation" is familiar enough.

The first of the two proposals I will call "restitutionism." I use that term in a rather narrow sense, to refer precisely to the idea that the right to punishment is a right to restitution. Thus, in criticizing "restitutionism," that is all I have in mind. I also use the word 'restitution' itself in a rather special sense, such that punishment is not instrumental to restitution. Rather-or at any rate that is how I choose to understand the proposal-punishment is constitutive of restitution, not a means to it. ${ }^{11}$

But now, how is the relevant notion of restitution to be understood? Wrongful actions usually cause harm, and it is generally believed that the perpetrator of such harm ought to compensate the victim in some appropriate way. But it is not obvious that punishment could serve as such compensation (as opposed to being a means to

\footnotetext{
10 For views of roughly this type, see Whiteley (1998) and Barton (1999). To clarify, I am neutral about whether there exists such a right to psychological benefits. I am only concerned to deny that a right to punishment is derivable from it.

11 Cf. Hershenov (2010, p. 50). But contrast ibid., p. 44.
} 
it - see below). Compensation for what, one is likely to ask ${ }^{12}$ The natural answer here, and perhaps the only one, is to distinguish between the harm the offense causes and the wrong it does, and then maintain that punishment compensates the victim for the wrong as opposed to the harm. ${ }^{13}$ Let us grant that wrongful actions are right violating actions. What, then, would compensating for the violation as such amount to? Such compensation would doubtless make sense, if the wrong were itself a kind of harm, in the sense that the victim has reason to want to avoid it, even apart from whatever other harm he suffers on account of the offense. ${ }^{14}$ If so, we could presumably say that part of what the victim is owed is compensation for the wrong. Now, perhaps it is true that punishment essentially provides a non-psychological benefit to the victim. And perhaps it is also true that this benefit is in addition to whatever other benefits compensation might bring. If so, punishment could indeed serve as compensation for the extra harm involved in the wrong.

But even these rather strong assumptions are insufficient to yield a right to punishment, for we still lack an explanation of what is so special about punishment as compensation. If being wronged is simply a way of being further harmed, then, some other form of compensation could do just as well, such as a cash payment. I assume here what I take to be the standard view of adequate compensation: "Something fully compensates a person for a loss if and only if it makes him no worse off than he otherwise would have been" (Nozick 1974, p. 57). Yet I would maintain that, if there is indeed a right to punishment, receiving "adequate compensation" thus defined does not satisfy that right. If the right is waivable, which can certainly be questioned, one might prefer to take the money instead, but that does not mean that the content of one's right is "punishment-or-compensation."

Apparently, then, if we are to make sense of a right to punishment as compensation, that compensation must be for the wrong as such, not for the wrong understood as a kind of harm, and it cannot be compensated in the way harms are. Groping around for a way of understanding that obscure idea we turn inevitably to the no less obscure, but also familiar, Hegelian idea of punishment as an "annulment" of the crime. ${ }^{15}$ Among contemporary defenders of something like that idea, Jean Hampton stands out (Hampton 1992a, b) — though she rarely uses the term "annul." Her view has been ably criticized by others, and I have nothing to add to that critique beyond noting that it gives us strong reason to doubt the prospects of a plausible account of a right to punishment based on Hampton's writings. ${ }^{16}$ However, Daniel Farnham (2008) has attempted to resuscitate the theory, and it is worth our while to consider

\footnotetext{
12 To be fair, most writers talk of restitution, in the usual sense of compensation for harm, as a substitute for punishment, rather than as a form of it. For a recent example, with many references, see Boonin (2008, pp. 218-275). Two writers who do talk of punishment as a kind of restitution are Holmgren (1989) and Hershenov (1999, 2010), though the former's view is rather remote from the kind I have in mind here.

13 Hampton (1992b) relies heavily on the harm/wrong distinction as part of a justification of punishment that could be understood as restitutionist, though she herself does not talk of "restitution".

14 Hampton speaks of the wrong as a kind of "moral injury" (e.g., 1992b, p. 1692).

15 For a helpful critical discussion of Hegel's view, see Brown (2001).

16 See, especially, Gert et al. (2004).
} 
his effort. The view he presents is not framed as a rights theory, and perhaps he would not wish it to be. Yet it could fairly easily be transposed into those terms, especially given the weak understanding of that notion I am employing. ${ }^{17}$

On Farnham's view, the wrong involved in crimes that merit punishment could be seen, at least in part, as affecting the relation between the two parties, offender and victim. The crime, he believes, creates a "relation of mastery" between offender and victim. This effect is distinct from the harm the crime does (2008, p. 613). The purpose of punishment is to undo the mastery relation. That is what "annulment" amounts to (ibid., p. 620). The crime itself, of course, cannot be undone, but the mastery relation supposedly continues to obtain afterwards, and would do so indefinitely unless ended by punishment. Ending the relation would not, then, amount to "compensation" as we normally understand that notion; but if the mastery relation is a kind of injustice to the victim, ending it might be something he could claim as a right. Further, the offender's mastery over the victim is ended by "effecting the mastery of the victim over the [offender]" (ibid.), thereby "realiz[ing] equality" between the two (ibid., p. 606). ${ }^{18}$

But what kind of relation between offender and victim does the word 'mastery' denote, and how can punishment undo it? Unfortunately these matters remain somewhat elusive. Farnham uses slavery as an example of mastery (p. 617), but that is not particularly helpful. A slave master must have the power to force the slave to do his (the master's) bidding, and to end the slavery relation is to end that power. A criminal offender need have no power over his victim once the crime is past. Indeed, socially and psychologically, the crime need not change the relationship between the parties at all. Yet it calls for punishment all the same. To be sure, a kind of socially recognized mastery relation might obtain if, and only if, the state refuses to punish the offender. By in effect condoning the crime, the state itself treats the offender as the "master." That is, it seems as if the state's decision not to punish gives the offender an inappropriate power over the victim. Perhaps that is what the mastery consists in.

But if that is indeed what Farnham means to say, he is surely confused. Though state inaction can help the offender master the victim, whether it does depends not on the decision not to punish the offender for a past crime, but rather on whether it will punish him for future crimes. If it will, his power is illusory, even if he and the victim both may quite reasonably believe the opposite. What is more, the state's unwillingness to punish a given offense could, and typically does, obtain even before the crime occurs, in which case it could be argued that the "mastery" relation between offender and victim is not generated by the crime but rather exists independently. It holds because of what the offender could do to the victim and get away with, rather

\footnotetext{
${ }^{17}$ Hampton on her part seems ambivalent on the role of victim's rights. Contrast the dismissive remarks in (1992a, p. 11) with the frequent appeals to "rights" and "entitlements" in (1992b). I should add that it might be possible to formulate Hershenov's view as well in terms of a right to restitution, though he himself does not (see note 10 above). However, as I find this view rather hard to pin down, I have elected not to do so.

${ }^{18}$ Farnham also contends that only the state can end the mastery relation, as "an impartial moral authority" (2008, p. 620). I will not address that aspect of his view.
} 
than what he has in fact done and gotten away with. A crime and subsequent state inaction could together drive home to the victim and others that this relation holds, but they do not by themselves create it. As Farnham is evidently, and rightly, after a relation that is generated by the crime, and would not have existed without it, the kind of power relation I have described could not be what he has in mind. However, until he manages to clarify his suggestion further, it will have to remain uncertain whether it could be employed to establish a right to punishment.

I turn now to the other proposal I mentioned. It differs from the one I have just been discussing in two ways. In the first place it conceives of punishment as instrumental to the compensation the victim is owed, rather than constitutive of it. Second, it conceives of this duty to compensate, corresponding to the victim's right, as belonging primarily to the offender, rather than the state. Specifically, the offender has an enforceable duty to compensate the victim, and the state has a duty to enforce the offender's duty. This so-called "duty view" of punishment has been vigorously defended recently by Victor Tadros (2011). On this view, the victim's right to compensation takes the form of a right to security. The idea is that the offender may, and typically must, compensate the victim not by paying him a sum of money but rather by protecting him from future harm, including harm for which he is not himself responsible. If he is unable or unwilling to provide that security through his own agency, he may legitimately be used as a means (by the state) to provide it. While punishing the offender need not benefit the victim specifically, by protecting him from future harm, Tadros argues that the victim could still indirectly have a right to it. He reasons as follows (ibid., p. 280): if offender $O$ owes victim $V$ protection as compensation for his offense and offender $O^{*}$ owes victim $V^{*}$ protection as compensation for his offense, and $O$ and $O^{*}$ are unable to protect their own victims but each is able to protect the other's victim, then they are typically obligated to come to an agreement to do so. This duty is also enforceable, and so it is in practice permissible, or even obligatory, for the state to punish $O$ to protect $V^{*}$ and to punish $O^{*}$ to protect $V$ (at least if the two offenders do not bring about the protection of their own accord).

Tadros notes that the above argument can only show that people who have already been victimized have a right to protection from future harms. To show why it is legitimate to punish offenders in order to protect merely potential victims, he suggests that victims can transfer their right to compensation to others, or at least to persons close to them (ibid.). Or, rather, the offender can meet his original obligation by protecting someone close to the victim, in lieu of protecting the victim himself. This protection could also count as a benefit to the victim.

While the above brief summary hardly does justice to Tadros' elaborate argument, it will have to do for our purposes. As with restitutionism, we are concerned only with the narrow question of whether the duty view gives us a justification of the frustrated crime victim's reaction-a question that perhaps does not concern Tadros. ${ }^{19}$ Further, the answer to that question seems negative. I will not pause to ask

\footnotetext{
${ }^{19}$ Like Hampton's view, the duty view, as a justification of the practice of punishment, has been subjected to much criticism. See, in particular, special issues of the journals Law of Philosophy (vol. 32, issues 1 and 2/3, 2013) and Criminal Law and Philosophy (vol. 9, issue 1, 2015) devoted to Tadros' book The Ends of Harm (including replies by Tadros).
} 
how much of a problem, if any, that answer poses for the duty view as a justification of the practice of punishment.

The source of the problem is precisely the fact that is characteristic of the duty view, namely that the victim's right corresponds, primarily, to a duty of the offender's. By contrast, I have assumed from the start that the state bears the corresponding duty, and have in fact not mentioned the offender's possible duties previously. To see why such an assumption is natural in the present context, consider that one arguable consequence of the duty view is that the victim is wronged just as much by the offender's successfully evading punishment as he is by the state's refusal to punish. Indeed, as the foundational duty underlying the institution of punishment on the duty view is the offender's, rather than the state's, it would if anything make sense for the victim to be more angry at the offender. Offhand, such a consequence is not attractive. While it might make sense to look with contempt at the offender's attempting to escape his punishment, I surmise that few will feel wronged by it, barring special circumstances (see below). Many (perhaps most) would, I suspect, take a pretty understanding attitude, knowing how unpleasant the punishment will likely be - though the less severe the punishment is relative to the crime, the less understanding they are likely to be. By contrast, pretty much any victim will react with outrage if the state slights its duty to find and punish the offender.

It could certainly be argued that the reason why the victim might not much care about the offender's evading punishment is that he sees no significant benefit to himself (or those he cares about) of this particular punishment-as opposed to the practice of punishment generally. ${ }^{20}$ Yet the relative causal insignificance of punishing any given individual should, prima facie, work equally strongly against the victim's resenting the state's failure to act in the particular case. The fact that victims do, and do properly, resent many such state failures to act suggests that the cause of the resentment is not the miniscule difference such failures make in terms of protecting these victims themselves (or those they care about). In the next section, I will consider a more plausible explanation.

In partial anticipation of that later discussion, though, I should note that the victim's attitude towards the offender's evading his punishment is determined in large part by the offender's attitude towards the victim. To illustrate the point, suppose the offender discriminates, meaning that he would have taken his punishment if the victim had been someone else, which in turn suggests that his unwillingness to accept his punishment in this particular case is due to his contempt for the victim (as opposed to others, or certain others), rather than the mere wish to avoid harm. In that case, the victim's resenting the offender would surely be appropriate. Yet it seems appropriate primarily as a reaction to one of many ways in which the offender could express his contempt for the victim. The latter may well have reacted similarly

\footnotetext{
${ }^{20}$ In this regard, the cases Tadros uses to argue for his view, in which the offender is used as a means to protect the victim from future harm - as a kind of compensation, which he is under an enforceable duty to provide-are plainly different. After all, such protection is an obvious benefit to the victim. As a consequence, if the offender tries to shirk his duty to compensate, or resist enforcement efforts, the victim may well have reason to resent him.
} 
if the offender had instead done so by, say, buying a full-page defamatory ad in the local paper.

Summing up, in this section I have distinguished between positive rights to (independently) beneficial treatment and positive rights to treatment that is not independently beneficial, and I have argued against a right to punishment of the former type, understood in two different ways. In the next section, I will consider the question of whether the frustrated crime victim's reaction can be explained by appeal to a right of the latter sort.

\section{Punishment, Communication, and Equality}

To find an alternative explanation of the frustrated crime victim's reaction, in terms of a positive right to treatment that is not independently beneficial, I wish to combine two ideas that have thus far played subordinate roles at best. The first is that of the state's action of punishing, or not punishing, as a form of communication. In other words, the state's decision in this regard is a way of "showing" or "expressing" something. To illustrate that idea in a related context, consider the view of Herbert Morris (1968) that punishing an offender is a way of showing that he is a person, responsible for his actions, and that it is thereby a way of showing respect for him as a person. Conversely, by not punishing the offender, the state conveys the image of him as not quite responsible for his actions, like a child, and this is insulting. Note also that the type of respectful treatment involved in punishment, if Morris is right, is not independently beneficial for the offender. ${ }^{21}$

This concern with communication should not come as a surprise in the case of punishment. Indeed, it is captured by one component of the definition of "punishment' I have used, namely that punishment is "reprobative," meaning that it involves some sort of public condemnation of the offender. ${ }^{22}$ Moreover, the fact that we are now talking about punishment administered, or not, by the state, as opposed to private individuals (including individuals in the state of nature) makes this communicative aspect particularly important. After all, the state speaks for all of us, as it were, and so what it communicates about us is particularly important to us, and to others.

The second idea is that the state ought to treat citizens as equals. We have already seen this idea at work in considering Farnham's view in the preceding section. On that view, remember, a crime effects a form of inequality between offender and

\footnotetext{
${ }^{21}$ For this type of interpretation of Morris, see Deigh (1984). It is a different question, of course, whether punishment itself is beneficial for the offender, and the idea that offenders have a "right" to punishment, as Morris holds, could be due to such distinct benefits. See Alm (2014).

${ }^{22}$ Feinberg (1965) may have been the first to draw attention to this important aspect of punishment. For a particularly influential later defense of the idea of punishment as "communicative," see Duff (2001). On his view, "punishment should be understood as a species of secular penance that aims not just to communicate censure but thereby to persuade offenders to repentance, self-reform, and reconciliation" (ibid., pp. xviii-xix). Also, successful punitive communication is not merely a contingent instrument to the latter ends but is rather an "intrinsically appropriate means" to them (ibid., p. 89).
} 
victim, which the punishment is supposed to correct. ${ }^{23}$ While this idea of "correcting" or "overcoming" inequality is obscure, as I noted, there is clearly a powerful intuition at work here. It is important to note, then, that the idea of equal treatment can manifest itself in two rather different ways. ${ }^{24}$ In the first place, the state could treat citizens (or persons) unequally in its distribution of burdens and benefits (though such inequality is not necessarily an injustice or right infringement). Consequently, this aspect of equal treatment is only relevant when there are burdens or benefits to be distributed in the first place. Hence, if punishment is not in itself a benefit to crime victims (independently of the way it is distributed), as I have argued, this first understanding of equal treatment is irrelevant to our concerns. That is, we could not say that the state's decision not to punish some crime, or not to criminalize some form of wrongdoing, amounts simply as such to treating one person, or group of persons, worse than others, by denying them some benefit it is willing to accord others.

The second way in which the state can fail to treat its citizens as equals shows us how this idea of equal treatment hooks up with the preceding one of punishment as communication. To see it, I note first that state actions can communicate value judgments about citizens, and if these judgments are false and invidious, they can wrong their targets. They are, then, a form of what has been called "judgmental injustice." ${ }^{25}$ What is more, the judgment expressed can be comparative: that is, it can say something about the value of one person or group of persons compared to others. In particular, then, the state's decision not to punish some offense could be said to express disregard for the victim, again compared to the offender and/or others. That is to say, it could express a (false) comparative value judgment about the victim and one or more others.

Given the rather weak understanding of a right with which we are working, it is easy enough to concede that persons have a right against their government not to suffer judgmental injustice of the type described, and in particular that that is true of crime victims. I concede, then, that in a sense I have just allowed what it has been my aim to deny, namely that there could be a right to punishment. However, it must be stressed that such a "right" would be very thin indeed. In the first place it is derived from a more fundamental right (to equal treatment), which tends to elicit the thought that the real cause of the frustrated victim's reaction is the unequal treatment rather than the non-punishment as such. Also, the right to equal treatment does nothing to justify the practice of punishment, as opposed to serving as a constraint on such a practice justified in some other way. (Cf. my earlier remarks in Sect. 1.) Thirdly, and relatedly, the right to equal treatment can yield only a comparative right to punishment, meaning a right to have one's victimizer punished provided that

\footnotetext{
${ }^{23}$ In this connection, we may also note Hershenov's claim that punishment "aims to restore the criminal and the victim to their status as equal citizens" (2010, p. 34). Similarly, Murphy writes that "[t]he idea of overcoming a perceived inequality is surely the dominant idea behind the metaphor of "getting even"" (2003, p. 25).

${ }^{24}$ See Alm (2010).

${ }^{25}$ See Feinberg (1974).
} 
those who offend against others are punished. (By a "comparative right," I mean one not to be treated worse than others in a certain respect.) By contrast, a right properly described as a "right to punishment" is naturally understood as a non-comparative right (to be treated in a certain way, regardless of how others are treated). ${ }^{26}$ That is, the right to equal treatment does not imply that crime victims who live in a society where no one is ever punished can complain that their right is violated.

I will return to this last, crucial point shortly, and argue that the implication is plausible. Before that, though, I wish to make some additional remarks about the type of right to equal treatment to which I have now appealed. In the first place, it helps explain my earlier observation that crime victims in a state whose victimizers are not punished have a complaint that unavenged victims of wrongdoing in the state of nature lack. After all, that appeal clearly makes sense when there is an agent charged with treating the person with the supposed complaint as an equal of every other member of some group. The state satisfies that condition. In the state of nature, though, there is no such agent. While it may be unpleasant, and perhaps to some degree demeaning, to be treated as of lesser worth by a random individual in the state of nature, yet to suffer the same treatment at the hands of the state is much worse.

We must also address the general question of what makes it the case that a given state action or inaction "expresses disregard" for some individual. This is not easy to say. It has to do with the still more general question of the conditions under which the state can be said to communicate some message through its actions and omissions. No answer to that general question is on offer here, but a consideration of the particular case that now interests us-i.e., failure to punish-could still tell us something useful. Strikingly, such failure could have a number of explanations, and not all of them support the charge of expressing disregard for the victim. For instance, suppose the relevant officials do their best to bring the offender to justice but simply find themselves unable to come up with the evidence. Hence, there is no punishment. While the state's failure to punish in this case might be said to convey that no one has been found fit to be punished for the crime, it does not seem to convey any disregard for the victim. After all, the explanation of the failure to punish is not that the state did not take the victim's plight seriously. In another case, by contrast, police and prosecutors are well aware of the offender's identity, yet do not lift a finger against him. The reason for this omission is their utter contempt for the victim. Such conduct, thus explained, does express disregard for the victim. In both cases, then, the message the state conveys is explained by the attitudes of those officials charged with the enforcement of the relevant laws. In another type of case, though, the law itself discriminates against the victim-or as is more likely, against some class of individuals to which he belongs. In that case, the attitudes of individual officials may not matter (at least as long as they follow the law). Regardless of

\footnotetext{
${ }^{26}$ Should we conclude that the right not to be exposed to false and invidious comparative judgments (by the state) is itself comparative? I think not. The central thing about the judgmental injustice is the false and invidious judgment, not that others have been spared it. Cf. Feinberg (1974, p. 303).
} 
their personal attitudes, it seems fair to say that the state under such circumstances expresses disregard for the victim (and others).

This excessively brief survey of different cases should give some idea, however incomplete, of what makes the state express disregard for the victim. To rehearse, we are at present entertaining the hypothesis that what explains the frustrated crime victim's reaction is the fact that the state expresses its disregard for him compared to others by not punishing those who victimized him, and that nothing else explains the reaction. A useful means of testing that hypothesis is to consider a state of the type mentioned earlier, one that refuses to punish as a matter of policy. (Below I will use the labels 'non-punishment state' and 'non-punishment society' for a state, and corresponding society, of this type.) If the hypothesis were true, crime victims in a nonpunishment society would have no reason to complain (qua crime victims). Would they? As should be clear, my answer is indeed that they do not, but that is a hard claim to prove. Still, I should at least take the opportunity to address some apparent reasons for thinking otherwise.

However, I should begin by conceding that it is possible to argue that even a nonpunishment state will inevitably end up treating its citizens unequally in a problematic way. To the extent that it does, the value of the test case can be questioned. It might be useful, then, to pause briefly to consider the justice of this charge. Two possible forms of unequal treatment in a non-punishment society stand out. In the first place, a policy of not punishing offenders might convey that they are somehow "worth more" than their victims, simply because they are in effect allowed to treat these victims as they please. This reaction is confused, however, as it ignores the fact that the state's policy is impartial. In other words, the situation is counterfactually symmetrical. While it is true that if $A$ offends against $B$, the state will not punish $A$, it is also true that it would have declined to punish $B$ if $A$ 's and $B$ 's roles had been reversed. Hence, $B$ could have no complaint on the ground that the state's decision not to punish $A$ somehow expresses a false judgment about $A$ 's worth relative to $B$ 's. For the truth of the counterfactual implies that no such judgment exists, or at least that it did not explain the decision not to punish $A .{ }^{27}$ (A general moral here is that in interpreting what is being communicated we must also consider counterfactual cases.)

The other way in which the non-punishment state treats its citizens unequally may be more substantial. For my talk above of "impartiality" and "counterfactual symmetry" could be dismissed as facile. While it may be true in some weak, formal sense-it might be charged - that a non-punishment state treats all its citizens alike by consistently refusing to punish those who infract against its laws, it then blithely disregards the many significant inequalities that will always exist between these same citizens, and which will in practice render the state's treatment unequal.

\footnotetext{
27 A complication is that the state's decision not to punish offender $O$ when offender $O *$ was, or would be, punished need not say anything about the victims of these crimes. The decision may instead reflect diverging judgments about $O$ and $O^{*}$. For instance, the state may treat $O$ as belonging to a privileged group that should be protected from punishment, no matter the victim, whereas $O^{*}$ is not a member of that group.
} 
For instance, some citizens will be rich and powerful, others poor and powerless. Some will have many steadfast and fearless friends or relatives, others none at all. Some will be ruthless and cunning, others feckless and foolish. And so forth. As a consequence, their ability to secure a measure of "justice" for themselves will also vary, and the same goes for the possible psychological benefits of such retaliation. Hence, one could insist that the state's toleration of these inequalities in effect conveys that they are acceptable (if perhaps deplorable)—and hence indirectly, or so the argument goes, that crime victims who cannot retaliate are less important than those who can, or that crimes perpetrated against the former are less of a concern than those perpetrated against the latter. This line of argument raises the difficult general issue of what message a state is sending by merely tolerating something. While I cannot answer that question here, it is at least worth stressing that, on a plausible interpretation, the inequalities identified above are not an intended consequence of the non-punishment state's refusal to punish, and that the intention of that policy, insofar as one can be identified at all, is precisely the wish to avoid punishment, as something undesirable or even morally indefensible. And, in any case, if the nonpunishment state wishes to counter its communicating false and invidious comparative judgments about certain crime victims, because of their lesser ability to retaliate successfully, surely there are ways of accomplishing this goal other than instituting a system of punishment. For instance, the state could take various other measures to reduce crime aimed against persons who would otherwise find it hard to enforce their own rights.

While the problem I have just noted probably cannot be disposed of completely, it is still worth returning to our earlier question of whether crime victims in a nonpunishment society have anything to complain about—and now simply granting that the state in such a society does not treat its citizens unequally in any morally problematic way. We can set aside here reasons to complain that are not specific to actual crime victims, such as reasons having to do with the absence of adequate crime prevention. We can also set aside the possible right to the psychological benefits of punishment, discussed in the last section. But what of the right to compensation? Should we say, as Tadros might, that crime victims in a non-punishment society can complain of inadequate compensation for the wrongful harms they have suffered? Though that may be the case, surely it need not. At least depending on circumstances, such a society could accomplish adequate compensation without punishment, not least by reducing crime through other means. (Tadros might insist that, if such crime reduction were possible, punishment would be an unjustified practice. I take no stand on that matter.) I would have to concede, though, that if the only way of compensating victims adequately is through a system of punishment, citizens of a non-punishment state may have reason to demand such a system.

Another possible argument for holding that people in a non-punishment society have reason to complain is the following. Earlier I denied that a crime victim in a non-punishment society suffers comparative disregard because of the state's refusal to punish-because of what I called the "counterfactual symmetry" of decisions not to punish. That is, I denied that this refusal, simply as such, embodies a false and invidious comparative value judgment about the victim and certain others-such as that offenses suffered by the victim are less important than otherwise similar 
offenses suffered by these others-because the state would have acted the same if the parties' roles had been reversed. But even if that be granted, it might be objected, surely the victim can complain of non-comparative disregard. That is, the state's failure to vindicate the victim through punishment conveys the false message that what happened to him was not wrong, or was at any rate not worth worrying about. In response, I would stress that what message state actions and omissions convey depends largely on how it usually acts in cases of the same kind (and hence determining the content of such "messages" essentially involves a kind of comparison). A non-punishment state's decision not to punish a given offender in a particular case does not convey any disregard for the victim of that particular offense. It is only when a state discriminates in its punishment decisions that it conveys objectionable judgments. If it punishes some crimes but not others, it might be taken to convey that punishment is, barring special circumstances, a proper response to wrongdoing and hence that those actions it fails to punish are not genuine wrongs. Perhaps a state (or "state") that not only consistently refrains from punishing offenders, but treats them exactly the same as it does non-offenders in every way (e.g., does not demand that offenders compensate their victims), and indeed does nothing whatever to prevent those deeds it outlaws (or "outlaws"), could be said to convey false, invidious, and non-comparative judgments about crime victims. After all, that would include a refusal even to condemn these actions in any way, even when prompted to do so. Yet it is hard to see how this state's mere refusal to punish carries any such message. But again, if the state were to take the extra step (unjustified, for all I have said) of punishing offenders, then its doing so selectively could (depending on what motivates the selection) amount to an expression of comparative disregard for those persons whose victimizers are not punished, and that would wrong them.

Having dismissed these reasons for doubt, I conclude, if only tentatively, that the frustrated crime victim's complaint indeed stems from the fact that the state has failed to treat him as an equal in the sense outlined above.

Acknowledgements I gratefully acknowledge a Grant from the Swedish Crime Victims Fund (Grant\# 09280/2009), which made work on this paper possible.

Open Access This article is distributed under the terms of the Creative Commons Attribution 4.0 International License (http://creativecommons.org/licenses/by/4.0/), which permits unrestricted use, distribution, and reproduction in any medium, provided you give appropriate credit to the original author(s) and the source, provide a link to the Creative Commons license, and indicate if changes were made.

\section{References}

Alm, D. 2010. "Equality and Comparative Justice.” Inquiry 53: 309-25.

Alm, D. 2014. "Is There a Claim to Deserved Punishment?" The Southern Journal of Philosophy 52: 403-25.

Barton, C. 1999. Getting Even. Chicago and La Salle. Open Court.

Boonin, D. 2008. The Problem of Punishment. Cambridge. Cambridge University Press.

Brown, S.P. 2001. "Punishment and the Restoration of Rights." Punishment \& Society 3: 485-500.

Cruft, R. 2013. "Why is it Disrespectful to Violate Rights?" Proceedings of the Aristotelian Society 113: 201-24. 
Deigh, J. 1984. "On the Right to Be Punished: Some Doubts.” Ethics 94: 191-211.

Dolinko, D. 1991. "Some Thoughts about Retributivism.” Ethics 101: 537-59.

Duff, R.A. 2001. Punishment, Communication and Community. Oxford. Oxford University Press.

Duff, R.A. 2016. "Legal Punishment," The Stanford Encyclopedia of Philosophy (Winter 2016 Edition), Edward N. Zalta (ed.), https://plato.stanford.edu/archives/win2016/entries/legal-punishment/.

Farnham, D. 2008. "A Hegelian Theory of Retribution.” The Journal of Social Philosophy 39: 606-24.

Feinberg, J. 1965. "The Expressive Function of Punishment." The Monist 49: 397-423.

Feinberg, J. 1974. "Noncomparative Justice." Philosophical Review 83: 297-338.

Gert, H., Radzik, L. \& Hand, M. 2004. "Hampton on the Expressive Power of Punishment." Journal of Social Philosophy 35: 79-90.

Hampton, J. 1992a. "An Expressive Theory of Retribution.” In W. Cragg (Ed.), Retributivism and its Critics. Stuttgart. Franz Steiner.

Hampton, J. 1992b. "Correcting Harms versus Righting Wrongs: The Goal of Retribution." UCLA Law Review 39: 1659-1702.

Hershenov, D. 1999. "Restitution and Revenge." Journal of Philosophy 96: 79-94.

Hershenov, D. 2010. "Punishment and Restitution." In J. Ryberg \& J.A. Corlett (Eds.), Punishment and Ethics. Basingstoke. Palgrave Macmillan.

Holmgren, M. 1989. "The Backward-Looking Component of Weak Retributivism." The Journal of Value Inquiry 23: 135-46.

Kershnar, S. 2000. "Reflexive Retributive Duties." Jahrbuch für Recht und Ethik 8: 533-47.

Locke, J. 1690. Second Treatise on Government. C.B. MacPherson (Ed.). Indianapolis. Hackett. 1980.

McMahan, J. 2009. Killing in War. Oxford. Oxford University Press.

Morris, H. 1968. "Persons and Punishment." The Monist 52: 475-501.

Murphy, J. 2003. Getting Even. Oxford. Oxford University Press.

Nozick, R. 1974. Anarchy, State, and Utopia. Oxford. Blackwell.

Raz, J. 1986. The Morality of Freedom. Oxford. Oxford University Press.

Simmons, A.J. 1991. "Locke and the Right to Punish." Philosophy \& Public Affairs 20: 311-49.

Tadros, V. 2011. The Ends of Harm. Oxford. Oxford University Press.

Wellman, C.H. 1995. "On Conflicts between Rights." Law and Philosophy 14: 271-95.

Whiteley, D. 1998. "The Victim and the Justification of Punishment." Criminal Justice Ethics 17: 42-54. 